\title{
Using Google Drive to facilitate a blended approach to authentic learning
}

\author{
Michael Rowe, Vivienne Bozalek and J ose Frantz
}

Corresponding author: Michael Rowe, Department of Physiotherapy, University of the Western Cape, Cape Town, South Africa, michael@realmdigital.co.za

Professor Vivienne Bozalek, Directorate of Teaching and Learning University of the Western Cape, Cape Town, South Africa, vbozalek@gmail.com

Professor J ose Frantz, Department of Physiotherapy, University of the Western Cape, Cape Town, South Africa, jfrantz@uwc.ac.za

\begin{abstract}
While technology has the potential to create opportunities for transformative learning in higher education, it is often used to merely reinforce didactic teaching that aims to control access to expert knowledge. Instead, educators should consider using technology to enhance communication and provide richer, more meaningful platforms for the social construction of knowledge. By using technology to engage in shared learning experiences that extend beyond the walls of the classroom, we can create opportunities to develop the patterns of thinking that students need to participate in complex, real world situations.
\end{abstract}

We used authentic learning as a framework to guide the implementation of a case-based, blended module in a South African physiotherapy department. Google Drive was used as a collaborative online authoring environment in which small groups of students used clinical cases to create their own content, guided by a team of facilitators. This paper describes an innovative approach to clinical education using authentic learning as a guiding framework, and Google Drive as an implementation platform. We believe that this approach led to the transformation of student learning practices, altered power relationships in the classroom and facilitated the development of critical attitudes towards knowledge and authority.

\section{Using Google Drive to facilitate a blended approach to authentic learning}

"The standard of thinking within the confines and parameters of the textbook, is an obstacle in finding creative ways for solving problems "

Student comment during this study

The past few decades have seen changes in our understanding of how learning happens, yet clinical educators still emphasise the transmission of content in their teaching practices (Graffam, 2007). While lectures are not inherently bad, information moves in one direction and students are rarely given opportunities to articulate their thinking. This means that any misconceptions they have are not shared, making it difficult for teachers to address errors in their understanding. This more traditional approach to learning, in which didactic methods 
predominate, assumes that knowledge is separate from context and regards it as a discrete "substance" that can be transferred between people (Seely Brown and Duguid, 1989).

However, learning is a situated activity in which meaningful knowledge construction happens in the same context in which the knowledge will be used (Lave and Wenger, 1991), rather than something that moves between people. When knowledge and context are separated, knowledge is seen by learners as a product of learning, rather than a set of tools for solving problems in a process of learning (Herrington and Oliver, 2000). In physiotherapy education, students are introduced to the tools - ways of thinking and knowing - of the professional community, allowing them access to what it means to be a practising member (Lave and Wenger, 1991). It is this engagement with contextually relevant problems using the tools of the profession that enables the student to move from a legitimate peripheral participant to a practising member of the community.

Clinical educators must therefore focus on the process of learning, going beyond teaching students what to know and what to do (Fraser and Greenhalgh, 2001). We must instead help them learn how to think. One way to develop critical thinking is through inquiry-based learning, in which students explore questions that they generate themselves (Justice et al., 2007a). It requires an environment that supports open discussion, questioning assumptions, and the critical evaluation of information, reflection, evidence and argument. Using principles of authentic learning, teachers can create environments reflect the context of the real world activity, encouraging students to think and behave as practising members of the community (Herrington and Oliver, 2000).

To help them navigate these learning environments, students need guidance in the form of a collaborative partnership to help them move from their current cognitive level to higher understanding. This social construction of knowledge is dependent on language and symbols as a means of communicating advanced ideas through structured dialogue (Vygotsky, 1978). Communication within a specific context is what enables students to make conceptual leaps, without which they would be unable to discern the tacit knowledge that is hidden from the novice (Laurillard, 2002). Communication and dialogue are therefore essential aspects of learning, as they provides the means by which students construct their own understanding of the world. By engaging in shared learning experiences that extend beyond the walls of the classroom, we can create opportunities to help students develop the tools they need to participate in complex, real world situations "in which coming to know is as important as knowing" (Cormier and Siemens, 2010, p. 38).

The emergence of digital technologies as an empowering medium for change in higher education has the potential to bring about transformative learning through enhanced communication, by providing richer and more meaningful platforms for the social construction of knowledge (Anderson, 2011; Veletsianos, 2011). However, the predominant use of technology in education has been to reinforce didactic teaching by improving the efficiency of content delivery through Learning Management Systems (Wilson, Parrish, and Veletsianos, 2008). We must therefore ask if the value of higher education is in carefully controlled access to expert knowledge, or in the engagement that arises through discussion (Cormier and Siemens, 2010)? If educators believe that the purpose of higher education is to 
deliver content, then it follows that their use of technology will merely reinforce didactic teaching methods that have a limited impact on qualitative learning outcomes (Herrington et al., 2009).

Much of the research into educational technology emphasises its role in information transfer, rather than as a transformative medium that leads to improved learning through structured interaction and flexible approaches to the curriculum. This paper describes the use of Google Drive to create a blended learning environment that facilitated interaction between students and teachers in online and physical spaces, where students completed authentic tasks that aimed to develop critical thinking.

\section{Method}

\section{Research setting and background}

The study was conducted in 2012, in a physiotherapy department at the University of the Western Cape, South Africa. It was initiated when the department received feedback from external examiners who indicated that final year students displayed a lack of reasoning and critical thinking during their clinical exams. The second year Applied Physiotherapy module (hereafter referred to as Applied) was selected as an appropriate module in which to evaluate the use of a theoretically- informed, blended approach to teaching and learning. In Applied, students learn the pathology, clinical presentation, and therapeutic management of common health conditions found in the South African healthcare system. Previously, students were provided with course readers covering the major concepts for each condition, and a lecturer went through the course readers with the students, using a predominantly lecture-based format.

Consequently, several changes were made to the module, including a move from lectures to case- based learning, and the integration of technology to facilitate different forms of communication, both of which were informed by social constructivist and situated theories of learning. We moved from having one lecturer in the classroom, to having between eight and ten facilitators, and used clinical cases to promote critical thinking and problem-solving in small groups. We used Reeves, Herrington and Oliver's (2002) ten characteristics of authentic tasks as a framework to guide our implementation of case-based learning using Google Drive. Google Drive is a free service from Google that includes word processing and presentation components, enabling multiple authors to work together in real time. It has version control, permissions-based sharing and instant messaging features that enhance the potential for collaboration. Students used Google Drive to collaboratively create notes in small groups both during and after classes, based on their exploration of the case. We used principles of authentic learning to design the cases and inform the teaching approach, which is briefly described below.

1. Authentic activities have real world relevance, matching as nearly as possible the tasks of professionals in practice. Facilitators used Google Drive to develop clinical cases, making regular adjustments based on student feedback and observations of activity in class and online. The cases were designed to encourage ways of thinking that would be 
expected in the real world management of patients. Using Google Drive enabled us to plan the teaching methods and modify variables at each stage of the case.

\section{[ ILLUSTRATION 1]}

2. Authentic activities are ill-defined and problems are open to multiple interpretations rather than easily solved by the application of existing algorithms. The cases were complex, requiring students to find associations between variables that were not explicitly linked. They needed to derive their own research questions after identifying gaps in their knowledge and understanding, conduct the research and then create their own notes in Google Drive, summarising and synthesising the information they had found.

\section{[ ILLUSTRATION 2 ]}

3. Authentic activities comprise complex tasks to be investigated by students over a sustained period of time. Each case ran over a three week period, with students and facilitators meeting in class for face-to-face contact three times a week, and interaction on Google Drive was used to supplement the classroom discussions. The task (i.e. clinical case) was not an isolated activity, with Google Drive being used both in class while students engaged in research and content creation, and afterwards when facilitators and peers gave feedback on the students' notes.

4. Authentic activities encourage students to examine the task from different theoretical and practical perspectives, using a variety of resources that require them to critically evaluate information. Facilitators reviewed students' case notes weekly, providing feedback using the comments feature, asking questions about missing information, unsubstantiated claims, and dubious sources. Students were able to respond within the comments, asking their own questions or clarifying their understanding. Other facilitators joined in the conversation, sharing their own experiences and thoughts.

5. Authentic activities require collaboration, which is integral to the task, so that success is dependent on it. Case notes were developed collaboratively by the student groups, and all notes were available to all other groups, as well as to facilitators. Each week, students created summaries of their case using the slideshow component of Google Drive, presented this in class, and then shared the summary with everyone. Google Drive also features an instant messenger, which allowed students and staff to discuss aspects of the case notes while looking at the document together, from different locations. Authentic activities provide the opportunity to reflect on learning, both individually and with others. Facilitators provided feedback to students within their case notes in the form of comments and questions, encouraging them to reflect on their assumptions and reasoning. Students were challenged on their statements and encouraged to articulate their understanding, as the questions were not asked to elicit information, but rather to stimulate further thinking.

\section{[ILLUSTRATION 4 ]}


6. Authentic activities can be integrated and applied across different subject areas and lead beyond domain-specific outcomes. Each case was designed to integrate research, ethical reflection, legal aspects of healthcare, and knowledge from other modules e.g. Anatomy. The case was designed so that it was not an isolated activity that was separate from other modules.

7. Authentic activities are seamlessly integrated with assessment in a manner that reflects real world assessment. Formative assessment was an inherent part of the activity, with peers and facilitators regularly challenging statements and assumptions that arose during the classroom sessions, and in the online notes. Students and facilitators used comments in Google Drive to ask questions regularly.

8. Authentic activities create polished products valuable in their own right rather than as preparation for something else. The notes that were created in Google Drive constituted the students' content for the module, making them an important product of the task. The questions for the tests at the end of each term were derived from both the students' notes and the facilitators' guides, which meant that the student notes had real value.

\section{[ ILLUSTRATION 5 ]}

9. Authentic activities allow multiple solutions and diversity of outcome, rather than having a single correct response obtained by the application of rules and procedures. Each groups' online case notes were different, reflecting the questions they answered after exploring their own understanding of the case. While facilitators ensured that the major concepts were addressed, students could take their own routes to achieving the objectives.

\section{Data collection}

Focus groups were held at the end of the first semester in 2012, including one of the authors (MR) and two groups of six students. This method was chosen because it encourages the creation of meaning though sharing ideas that individuals may not have thought of independently (Babbie and Mouton, 2006). All students in the second year class $(n=61)$ were asked if they were prepared to participate in a focus group, and 22 responded positively. Twelve students were invited to participate and were selected from both high and low ends of scales measuring their age, levels of online participation and their average marks in the module, in order to include as diverse a sample as possible. While there seems to be no strong evidence for the number of groups or participants in this approach, researchers agree that diversity of participants is important to reduce bias (Carlsen \& Glenton, 2011). Each focus group began with an explanation of the purpose and procedure of the discussion. Participants were asked to discuss the following topics, which were based on the major changes in the module: the move from lectures to case-based learning in small groups, and the use of Google Drive for students to collaboratively develop content. The discussions were recorded and the audio files sent for independent transcription, and then sent to participants for verification.

Data analysis 
The transcripts were analysed inductively to determine themes that emerged from participant responses (Elo and Kyngas, 2008). Inductive analysis was chosen as there is no evidence of any previous studies that evaluated the use of Google Drive to work collaboratively with the aim of developing critical thinking in any domain of healthcare education. Words and phrases with similar meanings were identified, coded and then organised into categories that best represented the emergent themes. The themes were analysed and discussed by the author and a co-author, and then independently reviewed by the third co-author, in order to reduce the potential for bias (Pope, Ziebland and Mays, 2000).

\section{Ethical considerations}

The study received ethical clearance from the University of the Western Cape Ethics Committee (project registration number: 09/8/16). Students volunteered to participate and were informed that there would be no negative consequences if they chose not to. All participants could withdraw at any time, including after the focus groups had taken place. Participants were informed that while participant anonymity was required, they could discuss the content of the focus group with others. Transcripts were anonymised on return from the transcriber, prior to being sent to participants.

\section{Results and Discussion}

Responses are presented in support of the major themes that emerged during the content. These themes include changes in student perceptions of their roles in the learning process, personal empowerment through self-directed learning, changing of power, and the development of critical thinking.

\section{Transforming student perceptions around learning}

While they were initially resistant to the approach, the following responses highlight how the students underwent a transformation in how they think about their role in learning, as well as a changing perception of what learning is.

When this new approach came it changed the whole thing. It forced me to understand why would I do this, instead of that. So it changes that perception that you can memorise your way through a degree.

My learning has changed. If I do the research, if I read the notes on Google Drive and if I go through it every day, I feel that I retained that information. When I come to write [tests], it just comes - like it's a part of me.

Being a student used to be like a job. So with this job I come to varsity from eight and knock-out at two and that's it, nothing to do with learning. Now it broke that fine line and redefined what learning was, it's not a classroom thing; it's a daily thing. It's not just learning from a book, it's...it's trying to find out how to learn.

These responses demonstrate that while we provided the opportunity for transformation, it was the students who took advantage of the opportunities (Veletsianos, 2011). The use of 
authentic learning to develop cases that we implemented in Google Drive enabled us to help change how students perceive their own role in the learning process. As part of this process, students had to create their own research questions after identifying gaps in their understanding, through discussion with peers and facilitators. Rather than being given content and told what to learn, the process required them to evaluate their own needs and respond appropriately, thereby empowering students to take control of their learning. This move towards thinking about learning represents a departure from traditional conceptions of learning, where students simply get on with it, without putting much thought into what it means to learn (Ovens, Wells, Wallis and Hawkins, 2011).

The following responses demonstrate how students perceived the inquiry-based component of the cases, and the development of critical thinking as part of an approach to lifelong learning.

I thought it was really effective that we have to explain to our peers what we have researched. So we have to have a good understanding of what we've found and not just copy-and-paste into our documents, but really be able to explain to other people so that they can understand.

I had to learn new ways of researching and how to find relevant and concrete information online, and to be selective of what information to choose.

So I found some good stuff the other night, but then I checked the date and I was like, that's older than me, I can't use that.

Using Google Drive afforded students a platform to develop the processes and skills they needed for the independent exploration of concepts and facts (J ustice et al., 2009). This critical interaction with information and with each other helped them to move towards autonomous learning, empowering them to control where, what and how they learn. The affordances of the technology must lead to a form of social interaction that goes beyond information exchange towards more reflective and in-depth analysis (Abrams, 2005). Specific features of Google Drive facilitated this process, including the "public" nature of the notes, which encouraged regular feedback from peers and facilitators, instant messaging that allowed students to chat with each other in the document window, and email notifications when changes or comments were made.

\section{[ ILLUSTRATION 6 ]}

\section{Changing power relationships as part of learning}

We used interaction in the online and physical space to intentionally change power relationships between teachers and students, guided by principles of authentic learning. The following responses highlight how students perceived these changing relationships.

I found that we've all got something to learn from each other. Even a lecturer has something to learn from a student...I think it has a lot to do with the interaction with facilitators. I've never had a problem with asking questions, but I still always felt like 
I'm going to look like an idiot if everyone knows this and I don't. I never feel like that any more...you're not going to think I'm an idiot.

I come from a background where we are taught protocol - this is your teacher, address him as 'Sir'. Now, coming with the type of relationship we have [in Applied] - that level of "superiority" has been reduced. And having [you] interested in things that I know, it's nice to discover that, hey, I also know something - I have something to say.

I like the way the teaching happens now, it broadens our minds, our ways of thinking. Like, okay, we didn't see that part, or, yes, we can think that way. You open your mind to a whole new world, a new way of thinking.

Power relationships are well-established in medical education, with teachers often using their power to "motivate" students with fear and shame (J arvis-Selinger, Pratt and Regehr, 2012). By intentionally changing these relationships we created a safe space, where both students and facilitators could normalise "not knowing" the answer. By liberating students from the necessity of being "right", they could explore their own understanding without fear of being exposed and shamed. The changing power relationship and reduction of authority can play a role in changing students' beliefs about who controls their learning, with an open environment helping them take on that responsibility (Bergstrom, 2010). This movement of authority away from the facilitators led to the development of personal empowerment among the students, enabling them to direct their own learning.

\section{Development of critical thinking}

We believe that this approach enabled students to change how they think about learning, relationships and content, in ways that led to critical thinking. The responses below demonstrate evidence of critical thinking around content, the profession and their teachers.

We're more confident in challenging ourselves. We're not just going to accept things. We're going to challenge ourselves and think further because we don't just want to know the basics. We want the knowledge to go further than what we see.

I believe that as a physio, you have to ask "Why?", every time you see something. Applied has changed our mindset. Every time we face a challenge, every time we see something...Why is this happening? Why is it happening this way?

It allowed me to scrutinise what my lecturers teach me. It opened that door - they're not always right, they don't know everything.

Text-based online learning tools have been shown to provide opportunities to express and share ideas, time for reflection, better understanding of in-class topics, and the development of critical thinking (Ghodrati and Gruba, 2011). If teaching is about "moving minds" to develop independent thinkers who will not bend to the will of teachers (Laurillard, 2012, p. 5), it is clear that these students did not simply accept the voice of authority. They grasped that 
knowledge is distributed and that the teacher is not the sole source of information (Veletsianos, 2011). Whether teachers are willing to give up this control and acknowledge to students that they may also be wrong will be a challenge to many.

In addition to the themes above, one student reported an undermining of the process by a colleague in the department, who was not involved in this module.

\begin{abstract}
Some people in the department are bashing [this module]. They say we don't know enough, but we're second years, we're not supposed to know everything. And when people are saying we're never going to get there because of the way this module's happening, that annoys me because I don't see it like that. We don't see the plan - these people [the other lecturers] probably don't see the plan either, we know they don't. We were told that we were going to fail before we even started - we were told it's not going to work. She didn't say she doesn't think it's going to work - she told us it's not going to work.
\end{abstract}

This demonstrates that this student took a critical stance and disagreed with the lecturer's point of view. She challenged their authority, positioning herself as a novice learner, and confident of where she is at this stage of her training. Attempts to modify teaching practices may have far reaching consequences for other lecturers, and should be approached with the understanding that they may resist the process. If colleagues perceive that an inquiry-based approach focuses more on skills than discipline-specific content, they may argue that it "undermines students' education" (J ustice et al., 2009). These curricular changes, while apparently beneficial for students, were nonetheless undermined by colleagues, suggesting that innovative approaches to teaching and learning may need institutional support in order to drive the process (Bozalek and Dison, 2012).

Finally, the use of Google Drive was demonstrated to fundamentally change teaching and learning practices in ways that went beyond simply increasing the efficiency of information distribution. The use of technology in this study emphasised the flexible approaches to the curriculum that present a practical means of changing practice for educators interested in teaching and learning. However, it should be noted that these changes required more time to develop and implement, and suggest the need for increased resources when considering this approach.

\title{
Limitations of the study
}

The students who volunteered to participate in the focus groups present a self-selecting bias in the study. These students may have had better experiences in the module, and may therefore have been more likely to point out positive outcomes. In addition, the focus groups described were held only once at the end of the first semester, meaning that these outcomes represent a single snapshot at an early stage of the process. 


\section{Conclusion}

We used Google Drive as a collaborative authoring platform to implement authentic learning tasks in the form of clinical cases, and used features of the online service to encourage interaction and discussion in order to develop critical thinking in a clinical context. We demonstrated that students' ways of thinking and being changed during the course of the module, facilitating a process of transformation around learning. This transformation was evident in their changing perceptions of their own role in the learning process, a movement of power away from teachers as students took control of their learning, and the emergence of critical attitudes towards knowledge and authority. If clinical educators aim to develop critical thinking within their students, they should consider the use of authentic activities that are integrated across physical and online spaces, using appropriate technology platforms that are informed by sound theoretical perspectives. 


\section{References}

Abrams, Z. (2005). Asynchronous CMC, collaboration and the development of critical thinking in a graduate seminar in applied linguistics. Canadian J ournal of Learning and Technology, 31, 23-47.

Anderson, T. (2011). Theories for learning with emerging technologies. In Veletsianos, G (Ed.). Emerging technologies in distance education (pp. 23-39). Edmonton: Athabasca University Press.

Babbie, E., \& Mouton, J . (2006). The practice of social research. Cape Town: Oxford University Press.

Bergstrom, P. (2010). Learning in higher education: Perspectives on the student-teacher relationship. International Review of Research in Open and Distance Learning, 11(2).

Bozalek, V. \&Dison, A. (2012). Using the human capabilities approach as a normative framework to evaluate institutional teaching and learning interventions at UWC. Accepted for publication in the South African J ournal of Higher Education.

Carlsen, B., \& Glenton, C. (2011). What about N? A methodological study of sample-size reporting in focus group studies. BMC medical research methodology, 11, 26.

Cormier, D., \& Siemens, G (2010). The open course. Through the open door: Open courses as research, learning, and engagement. Educause Review, July / August, 31-39.

Elo, S., \& Kyngas, H. (2008). The qualitative content analysis process. Journal of Advanced Nursing, 62(1), 107-115.

Fraser, S. W., \& Greenhalgh, T. (2001). Coping with complexity: Educating for capability.British Medical J ournal, 323(October), 799-803.

Ghodrati, N., \& Gruba, P. (2011). The role of asynchronous discussion forums in the development of collaborative critical thinking. Ascilite: Changing demands, changing directions (pp. 437-451).

Graffam, B. (2007). Active learning in medical education: Strategies for beginning implementation. Medical Teacher, 29(1), 38-42.

Herrington, J., Herrington, A., Mantei, J., Olney, I., \& Ferry, B. (2009). New technologies, new pedagogies: Mobile learning in higher education. University of Wollongong. Available from http:// ro.uow.edu.au/ newtech/ 
Herrington, J ., \& Oliver, R. (2000). An instructional design framework for authentic learning environments. Educational Technology Research and Development, 48(3), 23-48.

Jarvis-Selinger, S., Pratt, D.D. \& Regehr, G (2012). Competency is not enough: Integrating identify formation into the medical education discourse. Academic Medicine, 87(9), 1185-1190.

J ustice, C., Rice, J., Roy, D., Hudspith, B., \& J enkins, H. (2009). Inquiry-based learning in higher education: administrators' perspectives on integrating inquiry pedagogy into the curriculum. Higher Education, 58(6), 841-855.

J ustice, C., Rice, J ., Warry, W., Inglis, S., Miller, S., \& Sammon, S. (2007a). Inquiry in higher education: Reflections and directions on course design and teaching methods. Innovative Higher Education, 31(4), 201-214.

Laurillard, D. (2002). Rethinking university teaching: A conversational framework for the effective use of learning technologies. London: Routledge Falmer.

Laurillard, D. (2012). Teaching as a design science: Building pedagogical patterns for learning and technology. New York, NY: Routledge.

Lave, J . \&Wenger, E. (1991). Situated learning: Legitimate peripheral participation. New York, NY: Cambridge University Press.

Ovens, P., Wells, F., Wallis, P., \& Hawkins, C. (2011). Developing inquiry for learning: Reflecting collaborative ways to learn how to learn in higher education. London: Routledge.

Pope, C., Ziebland, S., \& Mays, N. (2000). Qualitative research in health care: Analysing qualitative data. British Medical J ournal, 320(7227), 114-116.

Seely Brown, J ., Collins, A. \& Duguid, P. (1989). Situated cognition and the culture of learning. Educational Researcher, 18(1), 32-42.

Veletsianos, G (2011). Designing opportunities for transformation with emerging technologies. Educational Technology, 51(2), 41-46.

Vygotsky, L. S. (1978). Mind in society: The development of higher psychological processes. Cambridge, MA: Harvard University Press.

Wilson, B., Parrish, P., \& Veletsianos, G (2008). Raising the bar for instructional outcomes: Towards transformative learning experiences. Educational Technology, 48(3), 39-44. 


\section{ILLUSTRATION 1}

\begin{tabular}{|c|c|c|c|}
\hline Table Heip & All changes saved in Dri & & \\
\hline - Ariat & $-1 \mathrm{~B} \quad I \quad \underline{\mathrm{U}}-\mathrm{IA}$ & 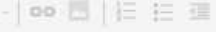 & 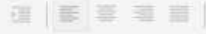 \\
\hline $\begin{array}{l}\text { Introduction to } \\
\text { section } 1 \text { of the case } \\
\text { Introduction to the } \\
\text { assignment } \\
\text { Setting group norms } \\
\text { Role allocation }\end{array}$ & $\begin{array}{l}\text { Lecture } \\
\text { Practical } \\
\text { Review objectives for } \\
\text { tomorrow's clinical } \\
\text { visit }\end{array}$ & $\begin{array}{l}\text { Clinical visit } \\
\text { Reflective blog posts }\end{array}$ & $\begin{array}{l}\text { Feedback in small } \\
\text { groups } \\
\text { Informal peer } \\
\text { evaluation } \\
\text { Finalise case notes } \\
\text { for the week } \\
\text { Group presentation }\end{array}$ \\
\hline
\end{tabular}

Objectives section 1

\section{Introduction to section 1}

You have received a referral for Mr J. Mr J was shot thrice by an opposing gang in the right arm, left tibia/ fibula area and left chest area. Entrance and exit wounds were found for bullets in arm and left tibia/fibula. The bullet that entered the chest had no exit wound but entry wound was found left Axilla. He was brought into the emergency unit several hours after the shooting. Mr $J$ now complains of numbness, weakness and burning sensation on right arm; weakness in right lower limb; only slight pain in left lower limb.

\section{Section 2}

A CT scan revealed that the bullet that entered in at the left axilla was lodged in T10-T11 foramen. An X-ray showed a

*-ray revealed haemopneumotherax on the left. $x$-showed comminuted fracture of tibia. The patient now complains of sharp chest pain, difficulty breathing. An operation was done to remove the bullet in the chest.

\section{Section 3}

$\mathrm{Mr} \mathrm{J}$ received a phone call from his gang members informing him that the person who shot him is going to make a hit on his wife and three kids. The nurses file indicated that $\mathrm{Mr} \mathrm{J}$ has had

\section{is going to make a hit on his wife and \\ Illustration 1: Using Google Drive to collaboratively develop clinical cases based on student} feedback during each case 


\section{ILLUSTRATION 2}

zols Table Help All changes saved in Drive

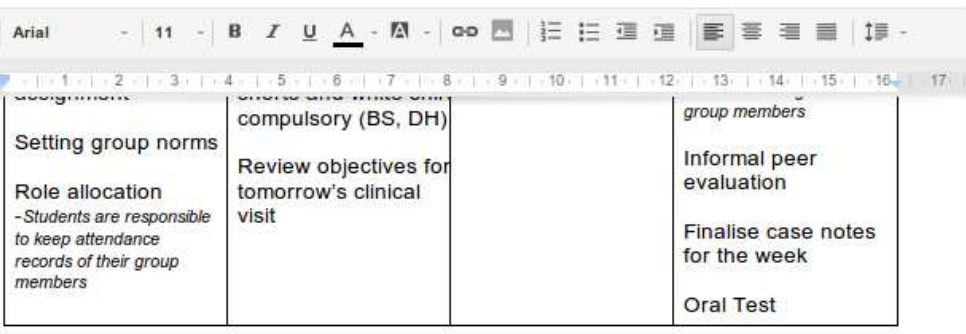

\section{Introduction to Case 6}

The highest cause of injury for males in South Africa is homicide, which is the fourth leading cause of death overall, preceded only by communicable and non-communicable diseases (Bradshaw et al.,2004).See http://www.mrc.ac.za/bod/estimatesresults.pdf for more /detail.

\section{Section 1}

You receive a referral for $\mathrm{Mr} \mathrm{J}$ on day one post-admission. After reading his medical folder you obtain the following information: He was brought into the emergency unit several hours after being shot, accompanied by an armed police officer. He was shot twice in the right arm and once in right chest area. Entrance and exit wounds were found for the bullets in the arm; the bullet that entered the chest had no exit wound and entered at the right axilla. During the attack he was struck with heavy brick on his left lower leg and presents with massive bruising and swelling. His right upper arm is now swollen, and he complains of numbness, weakness and a burning sensation in that area. He also complains of weakness in the right lower limb and only slight pain in the left lower limb. His current vital signs are: T: 36.5 degrees; RR: 26; HR: 100; BP: $130 / 90$. The doctor has stated that no mobilisation should be done.

Use the questions below as an overview for working on the 7 step process:

What do you know?

What do you think you know?

What do you need to find out?
What would your discharge and rehabiutation plan should we include this or rather remove it? I think we should remove it the facilitator should guide them in this direction

Comment-Resolve

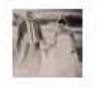

\section{Selected text:}

14:22 18 Sep-Re-open

\section{Lecture}

Or another siot for a lecture as they will not take that long with the 7 jump process?? Comment

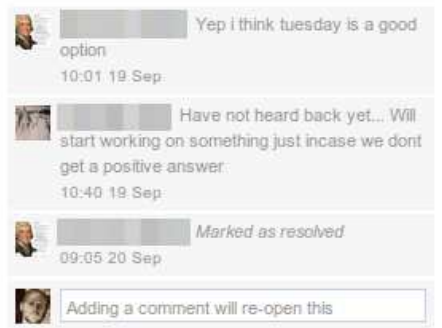

\section{Illustration 2: Example of the clinical cases that students were presented with, along with facilitator discussion around logistics, in the margin https://repository.uwc.ac.za/}




\section{ILLUSTRATION 3}

\section{Case 5 - Group J}

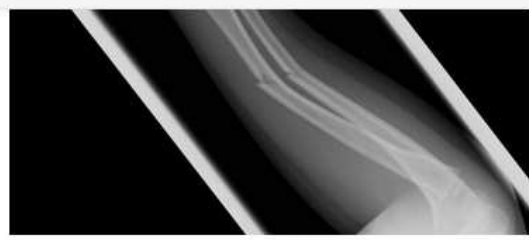

\section{Hypothesis}

We believe Tom has a GREENSTICK FRACTURE because the bones of a child are more pliable than the bones of an adult's, therefore the force that created the break only broke the outer part of the bone and caused the opposite side to bend. Usually, in an adult, the same amount of force would have broken the same bone completely, because their bones are not as pliable.

\section{Signs and Symptoms}

Symptoms of a broken wrist are severe pain and sometimes numbness of the forearm and hand. Signs include; any type of deformity to the wrist, elbow or forearm, tenderness, swelling and the inability to rotate (pronation and supination) the forearm.

\section{Physiotherapy Management}

Isometric-contractions: during the time when the patient is still in cast, to prevent muscle
Aug 29, 06:48

ceciln 227

Aug 26, 19:44

an adamemery 1

Aug 26, 16:57

An capesbryan

Aug 24, 13:12

Erivkahsarah777

Aug 24, 12:25

in hayley 24

Aug 23, 06:56

incecilm 227

Aug 21, 14:04

ㅂ. ceciim 227

ivivahsarah777

Aug 21, 07:24

= cecilm227

Aug 20, 20:15

Erivkahsarah 777

Aug 16, 21:04

Eancy

Aug 15, 12:51

- truffie leigh

$\checkmark$ Show changes

Illustration 3: Students' case notes with version history visible, showing who had made contributions to the notes 


\section{Physiotherapy management}

1. Muscle tone

2. Strengthening

3. Range of motion

Test Flexion and extention due to Toms flexion contraction at the knee hidge joint.

4. Stretching

5. Education on joint protection

6. Home exercise plan

7. Education on pain reducing techniques

8. Muscle relaxation techniques

9. Splints or orthotics maybe be beneficial to help maintain normal bone and joint growth/prevent deformities during growth

\section{Physiotherapy Treatment according to Nalan, B. (2005)}

Heat ando cold therapy, massage, electrical stimulation, and ultrasound are the main modalities used to treat Juvenile arthritis. The aim for these treatments is to relieve pain and stiffness, reduce contractures in the muscles and train specific muscle groups.

\section{Heat therapy}

helps to decrease joint stiffness, increase flexibility of tendons, and decrease pain and muscle spasms.

\section{Cold treatment}

has an analgesic effect and vasoconstriction purposes in the inflamed joints during the acute period.

\section{Massage}

relieve pain and prevent adhesions in the subcutaneous tissues.

4. Electrical stimulation

used for children that have excessive muscle atrophy as well as children that cannot or does not exercise.

\section{hayley24j \\ 12.28 .24 Aug}

It is important that you expand on

the list. What muscle relaxation technique will you use? Where will you stretch and how are the stretches performed? What will the home exercise plan include? ETC

\section{Reply to this comment.}

\section{(2) Michael Rowe}

11:45 14 Aug

Memorising this list will not help you with any patient you're likely to see. For each item, you must explain what it means in the context of this patient.

\section{mohlahle}

10:18 20 Aug

Janine expand on specific muscles and joint movement affecteed

Illustration 4: Example of facilitator feedback and student interaction in the margins of the studentgenerated notes. 


\section{ILLUSTRATION 5}

ICF CF, Pancreatitis, Bronchi \& Diabetes

File Edit View Help

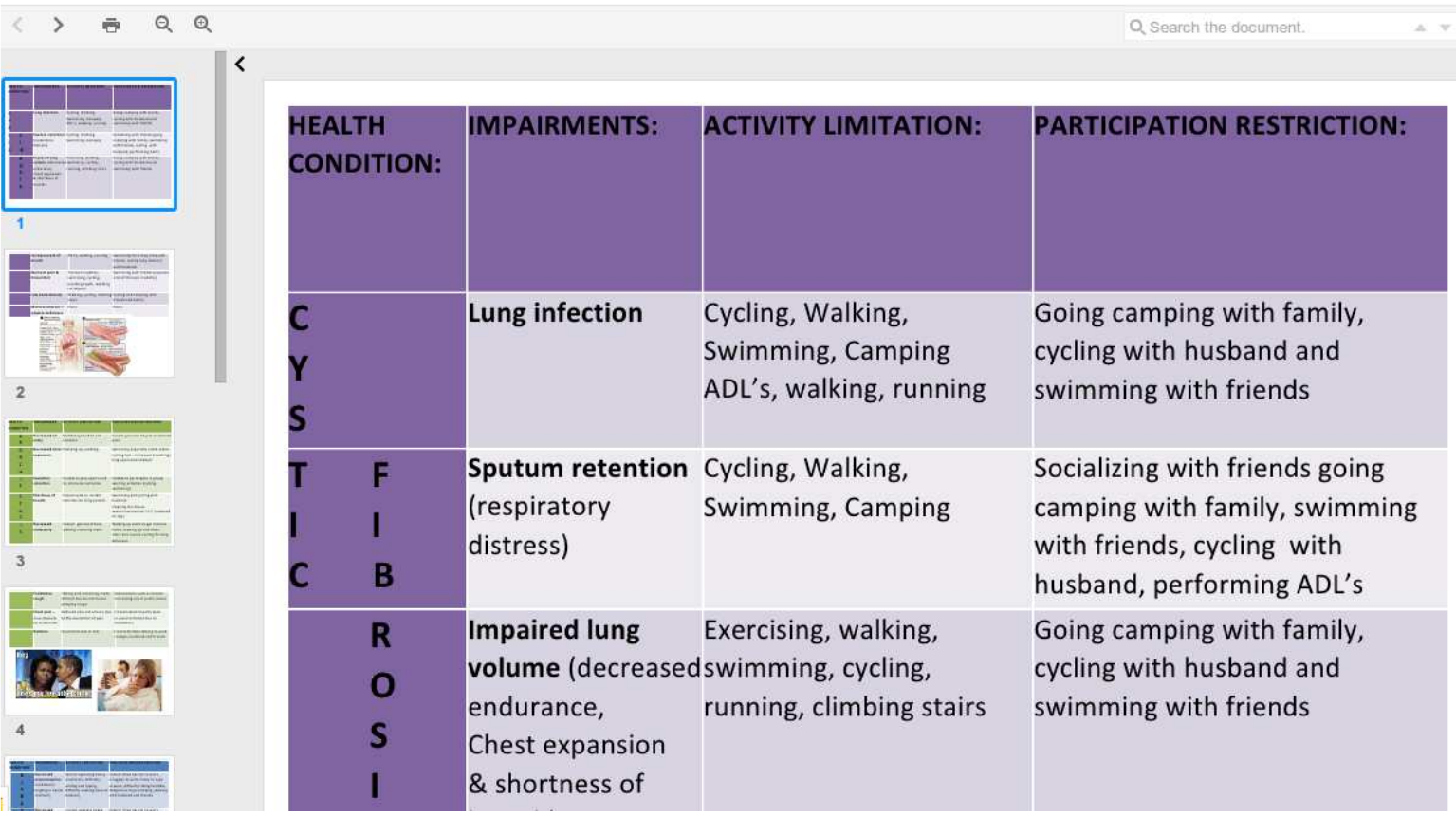

Illustration 5: Example of a weekly summary, presented for feedback and then shared with all groups

\section{https://repository.uwc.ac.za/}




\section{Cecil replied to a comment on Case 5 - Group J}

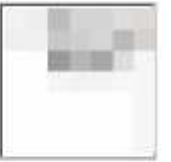

\section{Michael \\ include}

Try to get away from writing long lists. This is not useful. Rewrite the list as a narrative. Ask me if you don't know what a narrative is.

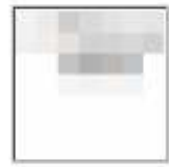

\section{Toni-Leigh}

$\mathrm{i}$ think $\mathrm{i}$ have an idea of what a narrative is but please explain just in case ism mistaken.

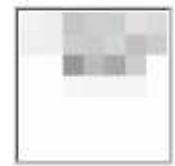

\section{Michael}

Think of it like a story. E.g. "The patient might present with a cough that could be productive or non-productive. The cough may be associated with SOB that is exacerbated by exercise or activity. Wheezing may also be a problem. If the respiratory symptoms are very bad, the patient may present with a bluish colour to the lips and face, known as cyanosis." Can you see how I blend all the respiratory symptoms together into a story. This story demonstrates that you've thought about the symptoms and can link them together. Hope that helps.

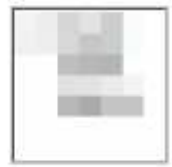

\section{Cecil}

Super helpful

You received this email because you are mentioned in this thread, Change what Google Docs sends you. You can reply to this email to reply to the comment.

Illustration 6: An email highlighting a conversation in the comments of case notes, between two students and a facilitator 